\title{
Modeling the compressive strength of geopolymeric binders by gene expression programming-GEP
}

\author{
Ali Nazari ${ }^{\mathrm{a}, \mathrm{c}}$, F. Pacheco Torgal ${ }^{\mathrm{b}, *}$ \\ ${ }^{a}$ Department of Concrete and Geopolymer, WorldTech Scientific Research Center (WT-SRC), Tehran, Iran \\ ${ }^{\mathrm{b}}$ University of Minho, C-TAC Research Centre, Guimarães, Portugal \\ ${ }^{\mathrm{c}}$ Department of Modeling and Simulation, WorldTech Scientific Research Center (WT-SRC), Tehran, Iran
}

\section{A R T I C L E I N F O}

\section{Keywords:}

Geopolymers

Compressive strength

Gene expression programming

\begin{abstract}
A B S T R A C T
GEP has been employed in this work to model the compressive strength of different types of geopolymers through six different schemes. The differences between the models were in their linking functions, number of genes, chromosomes and head sizes. The curing time, $\mathrm{Ca}(\mathrm{OH})_{2}$ content, the amount of superplasticizer, $\mathrm{NaOH}$ concentration, mold type, aluminosilicate source and $\mathrm{H}_{2} \mathrm{O} / \mathrm{Na}_{2} \mathrm{O}$ molar ratio were the seven input parameters considered in the construction of the models to evaluate the compressive strength of geopolymers. A total number of 399 input-target pairs were collected from the literature, randomly divided into 299 and 100 sets and were trained and tested, respectively. The best performance model had 6 genes, 14 head size, 40 chromosomes and multiplication as linking function. This was shown by the absolute fraction of variance, the absolute percentage error and the root mean square error. These were of $0.9556,2.4601$ and 3.4716 for training phase, respectively and $0.9483,2.8456$ and 3.7959 for testing phase, respectively. However, another model with 7 genes, 12 head size, 30 chromosomes and addition as linking function showed suitable results with the absolute fraction of variance, the absolute percentage error and the root mean square of $0.9547,2.5665$ and 3.4360 for training phase, respectively and $0.9466,2.8020$ and 3.8047 for testing phase, respectively. These models showed that gene expression programming has a strong potential for predicting the compressive strength of different types of geopolymers in the considered range.
\end{abstract}

(c) 2013 Elsevier Ltd. All rights reserved.

\section{Introduction}

Geopolymers have attracted a lot of attention as a result of their excellent mechanical properties, durability and cost-efficiency (Duxson, Provis, Van Lukey, \& Deventer, 2007; Pacheco-Torgal, Castro-Gomes, \& Jalali, 2008a). Different alkali activators play a major role in producing geopolymers by dissolving silica and alumina from the raw material and thus forming aluminosilicate structures (Pacheco Torgal, Gomes, \& Jalali, 2008). Raw materials include, ordinary Portland cement (Tailby \& MacKenzie, 2010), metakaolin (Muñiz-Villarreal et al., 2011), rice husk-bark ash (Nazari, Bagheri, \& Riahi, 2011), different types of fly ash (Chindaprasirt, Chareerat, \& Sirivivatnanon, 2007; Temuujin, Minjigmaa, Lee, Chen-Tan, \& van Riessen, 2011; Wang, Jia, He, \& Zhou, 2011), ground granulated blast furnace slags (Bernal, Gutierrez, Delvasto, \& Rodriguez, 2010), volcanic ashes (Lemougna, MacKenzie, \& Melo, 2011), red mud (He, Zhang, Yu, \& Zhang, 2012) and the other slags (Onisei et al., 2012).

\footnotetext{
* Corresponding author. Tel.: +351 253 510200; fax: +351 253510213 .

E-mail addresses: f.pachecotorgal@gmail.com, torgal@civil.uminho.pt (F. Pacheco Torgal).
}

Artificial intelligence (AI) approaches are applied in artificial neural networks (ANNs), fuzzy logic, support vector machines, genetic algorithms (GA), genetic programming (GP) and so on. Each approach offers merits in particular applications (Tsai, 2011). Although there are several experimental studies performed as stated above, there is still lack of explicit formulation for the compressive strength of different types of geopolymers. The use of genetic programming for formulation of the compressive strength of geopolymers has in fact rarely been reported (Nazari, 2012a, 2012b; Nazari, Riahi, Khalaj, Bohlooli, \& Kaykha, 2011). In comparison, besides classical regression techniques, soft computing applications such as genetic programming (GP) for the explicit formulation of the properties and the performances of concrete have begun to arise (Cevik \& Sonebi, 2009; Sarıdemir, 2010; Tanyildizi \& Cevik, 2010). Tanyildizi and Cevik (2010) applied GP for modeling the mechanical performance of lightweight concrete containing silica fume exposed to high temperature. Cevik and Sonebi (2009) modeled fresh and hardened properties of self-compacting concrete containing pulverised fuel ash through the use of GP. For predicting the compressive strength of concretes containing rice husk ash, (Sarıdemir, 2010) applied GP, as well. GP is more advantageous than classical regression techniques. While 
regression techniques are often based on predefined functions, on the other hand, in genetic programming there is no predefined function to be considered. The latter adds or deletes various combinations of parameters so they can be considered for the formulation that best fits the experimental results. GP has proven to be an effective tool to model and obtain explicit formulations of experimental studies (Tanyildizi \& Cevik, 2010).The aim of this work is to develop suitable GP models for evaluating the compressive strength of different type of geopolymers and arises as a result of the limited works on the prediction of geopolymers properties with soft-computing techniques. A total number of 399 pairs of input-target values were collected from the previous works (Pacheco-Torgal, Castro-Gomes, \& Jalali, 2007, 2008b; Pacheco-Torgal, Moura, Yining Ding, \& Jalali, 2011). The curing time, $\mathrm{Ca}(\mathrm{OH})_{2}$ content, the amount of superplasticizer, $\mathrm{NaOH}$ concentration, mold type, aluminosilicate source and $\mathrm{H}_{2} \mathrm{O} / \mathrm{Na}_{2} \mathrm{O}$ molar ratio were considered as input parameters to predict the compressive strength of geopolymers as output. Six different GP models were proposed for the prediction of the compressive strength of geopolymers in which their linking functions, number of genes, chromosomes and head sizes were different. The entire models were trained and tested by randomly divided 299 and 100 input-target pairs, respectively.

\section{Data collection}

The input-target values were collected from the previous works (Pacheco-Torgal et al., 2007, 2008b, 2011). The aluminosilicate sources in these works were tungstenpa mine wastes (PachecoTorgal et al., 2007, 2008b) and metakaolin (Pacheco-Torgal et al.,
2011). The tungsten mine waste mud used was subjected to a thermal treatment at $950{ }^{\circ} \mathrm{C}$ during $2 \mathrm{~h}$ (Pacheco-Torgal et al., 2007, $2008 \mathrm{~b})$. The metakaolin used in the study was subjected to a thermal treatment at $650^{\circ} \mathrm{C}$ during a few seconds using a flash calcination apparatus (Pacheco-Torgal et al., 2011). Distilled water was used to dissolve the sodium hydroxide flakes to avoid the effect of unknown contaminants in the mixing water. The alkaline activator was prepared prior to use. The sand, mine waste mud (or metakaolin) and calcium hydroxide were dry mixed before adding the activator. Compressive strength data was obtained using $50 \times 50 \times 50 \mathrm{~mm}^{3}$ cubic specimens according to ASTM C109 for tungsten mine wastes-based geopolymers and $160 \times 40 \times$ $40 \mathrm{~mm}^{3}$ cubic specimens according to EN 1015-11 for metakaolin-based ones. The fresh mortar was cast and allowed to set at room temperature for $24 \mathrm{~h}$ before being removed from the molds and kept at room temperature for other days until tested in compression. Compressive strength for each mortar mixture was obtained from an average of three cubic specimens. The full experimental procedure for obtaining strength values can be achieved from Refs. Pacheco-Torgal et al. (2007, 2008b, 2011).

\section{Genetic programming and gene expression programming theory}

Sarıdemir (2010) mentions that GP is an extension of the genetic algorithms proposed by Koza (1992). The latter defines GP "as a domain independent problem solving approach in which computer programs are evolved to solve, or approximately solve, the problems based on the Darwinian principle of reproduction and analogs of naturally occurring genetic operations such as reproduction,

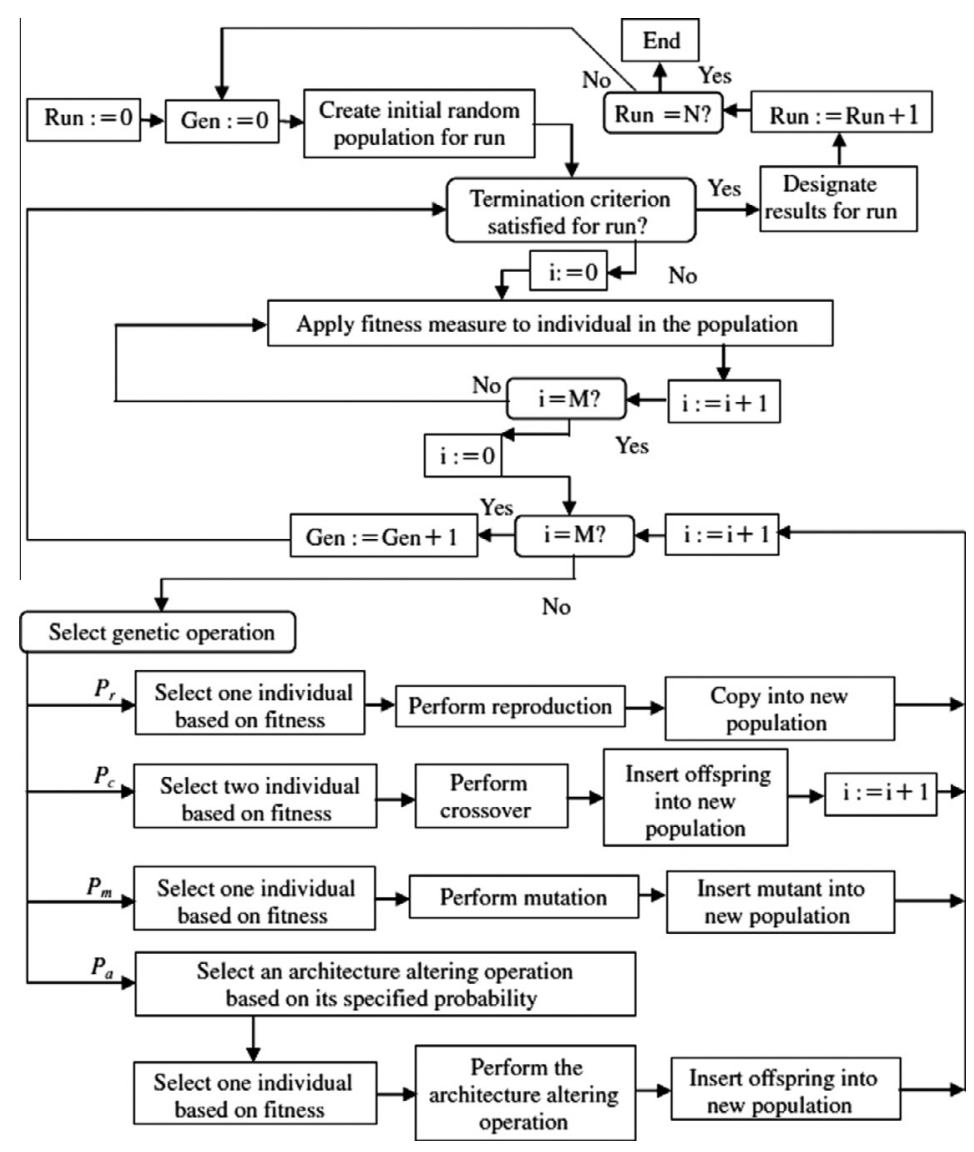

Fig. 1. Genetic programming flowchart (Sarıdemir, 2010). 

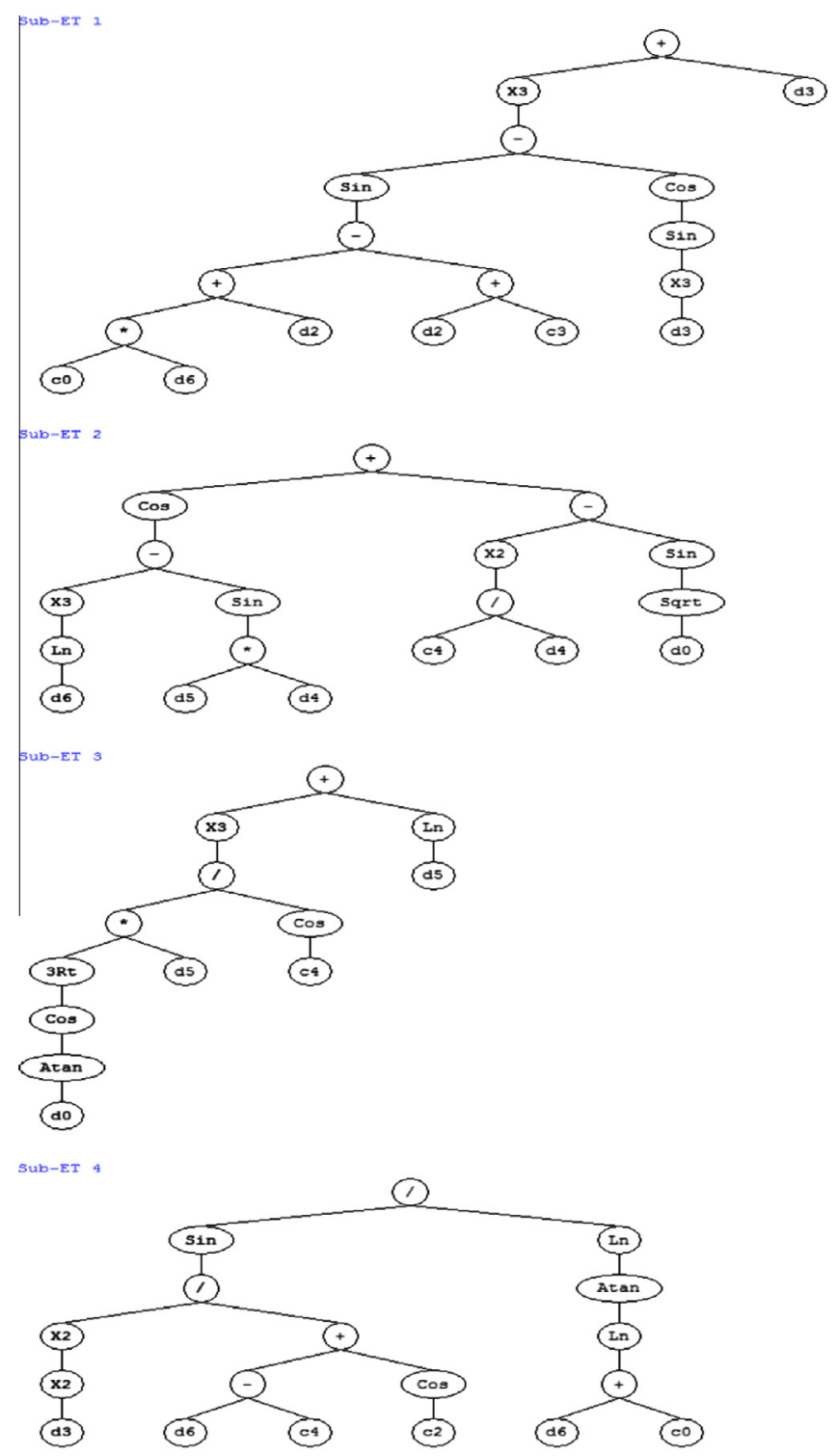

SUL-ET 5

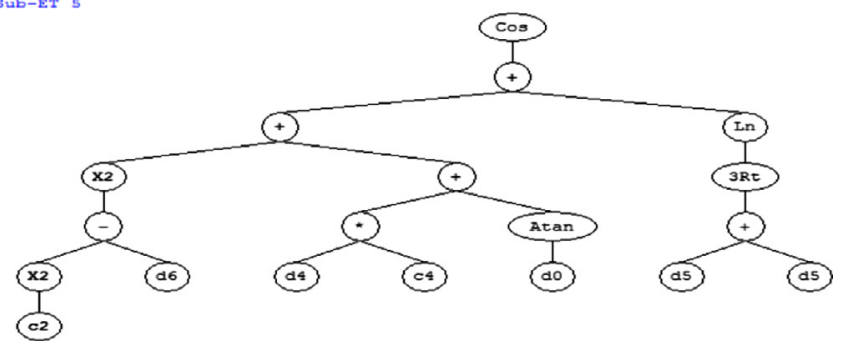

Fig. 2. Expression tree with 5 gens and addition as linking function for predicting compressive strength values of different geopolymers in GEP1 model.

crossover and mutation". Fig. 1 shows how GP can reproduce computer programs to solve problems. This figure is a flowchart showing the executional steps of a GP run. According to Sarıdemir (2010) the GP approach evolves through the action of three basic genetic operators: "reproduction, crossover and mutation. In the reproduction stage, a strategy must be adopted to the selection of which programs should "die". In the implementation, a small percentage of the trees with the worst fitness are "killed". The population is then filled with the surviving trees according to accepted selection mechanisms“.
Sandemir describes the GP problem solving in five steps:

(1) The set of terminals: A set of input variables or constants.

(2) The set of primitive functions: A set of domain specific functions used in conjunction with the terminal set to construct potential solutions to a given problem. For symbolic regression this could consist of a set of basic mathematical functions, while Boolean and conditional operators could be included for classification problems.

(3) The fitness measure: Fitness is a numeric value assigned to each member of a population to provide a measure of the appropriateness of a solution to the problem in question.

(4) The parameters for controlling the run: This includes the population size and the crossover and mutation probabilities.

(5) The method for designating a result and the criterion for terminating a run: This is generally a predefined number of generations or an error tolerance on the fitness (Koza, 1992). It should be noted that the first three components determine the algorithm search space, while the final two components affect the quality and speed of search (Sarıdemir, 2010).

\section{Artificial neural networks parameters and structure}

In the present work, as seen in Figs. 2-7, the expression trees of six different GEP approach models named GEP1 to GEP6 were constructed for compressive strength $\left(F_{S}\right)$ values of the considered geopolymers. d0, d1, d2, d3, d4, d5 and d6 in Figs. 2-7 represent the values for curing time $(T), \mathrm{Ca}(\mathrm{OH})_{2}$ content $(C)$, the amount of superplasticizer $(S)$, $\mathrm{NaOH}$ concentration $(N)$, mold type $(M)$, aluminosilicate source $(A)$ and $\mathrm{H}_{2} \mathrm{O} / \mathrm{Na}_{2} \mathrm{O}$ molar ratio $(H)$, respectively in accordance to the type of collected data from the previous works (Pacheco-Torgal et al., 2007, 2008b, 2011).

Table 1 also shows the range of each input parameters and that of the output parameter. In GEP1-GEP6 models, the number of genes (Sub-ETs), chromosomes and head size together with linking functions were different. 5 Sub-ETs were used for GEP1 and GEP4, six for GEP2 and GEP5 and six for GEP3 and GEP6 models. In GEP1GEP3 models, addition was employed as linking function while multiplication was used for GEP4-GEP6 approach models. In training and testing of GEP1-GEP6 models constituted with different Sub-ETs and linking functions, $T, C, S, N, M, A$ and $H$ were utilized as input data and $F_{S}$ as independent output data. Among 399 experimental sets collected from the literature, 299 sets were randomly chosen as a training set for GEP1-GEP6 modeling and the remaining 100 sets were used for the testing of the generalization capacity of the proposed models.

According to Sarıdemir (2010) for this problem, firstly, the fitness, $f_{i}$, of an individual program, $i$, is measured by:

$f_{i}=\sum_{j=1}^{C_{t}}\left(M-\left|C_{(i j)}-T_{j}\right|\right)$

where $M$ is the range of selection, $C_{(i, j)}$ is the value returned by the individual chromosome $i$ for fitness case $j$ (out of $C_{t}$ fitness cases) and $T_{j}$ is the target value for fitness case $j$. If $\left|C_{(i j)}-T_{j}\right|$ (the precision) is less than or equal to 0.01 , then the precision is equal to zero, and $f_{i}=f_{\max }=C_{t} M$. In this case, $M=100$ was used, therefore, $f_{\max }=1000$. The advantage of this kind of fitness functions is that the system can find the optimal solution by itself (Sarıdemir, 2010). All of the models were allowed to experience more than 100,000 iterations to ensure maximum fitness was gained.

"The set of terminals $T$ and the set of functions $F$ to create the chromosomes are preferred, namely, $T=\{T, C, S, N, M, A, H\}$ and four basic arithmetic operators $(+,-, *, /)$. Some basic mathematical functions (Sqrt, third root, $x^{2}, x^{3}$, In, Exp, sin, cos, Arctan) were also used. Another major step is to choose the chromosomal tree, i.e., 


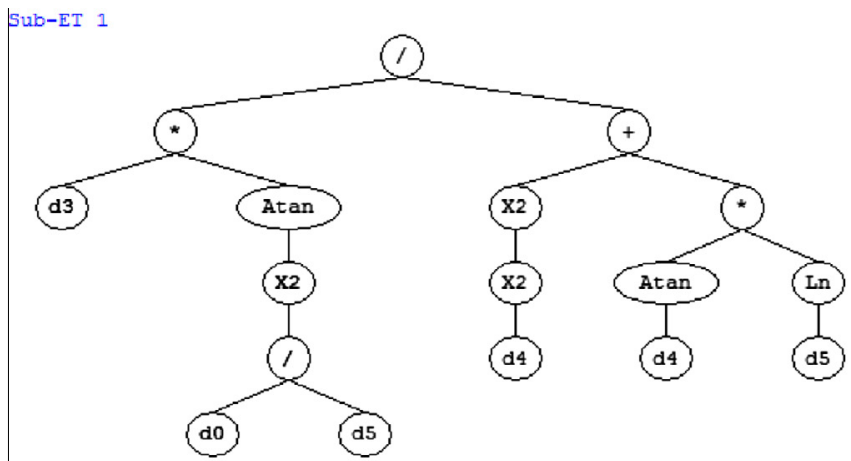

Sub-ET 2

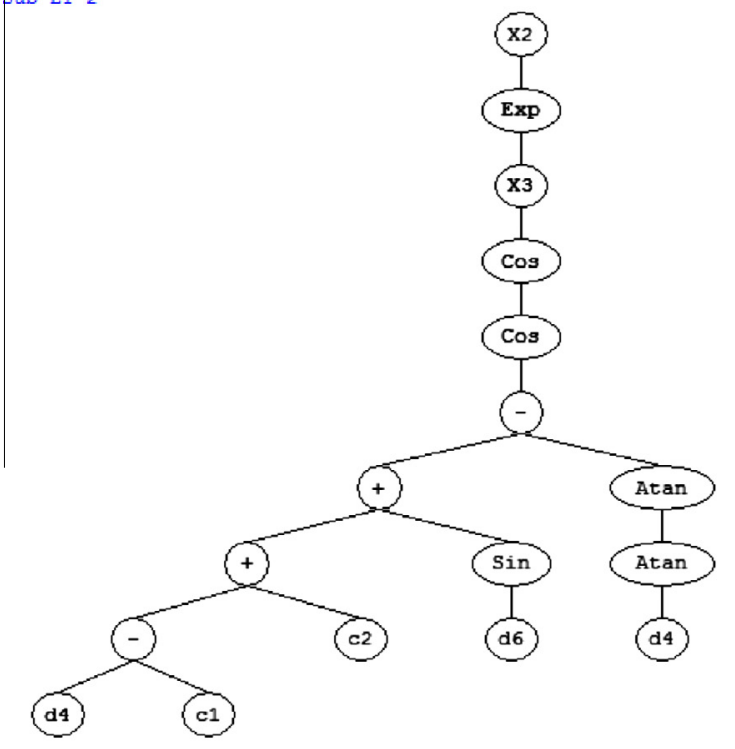

Sub-ET 3

(d3)
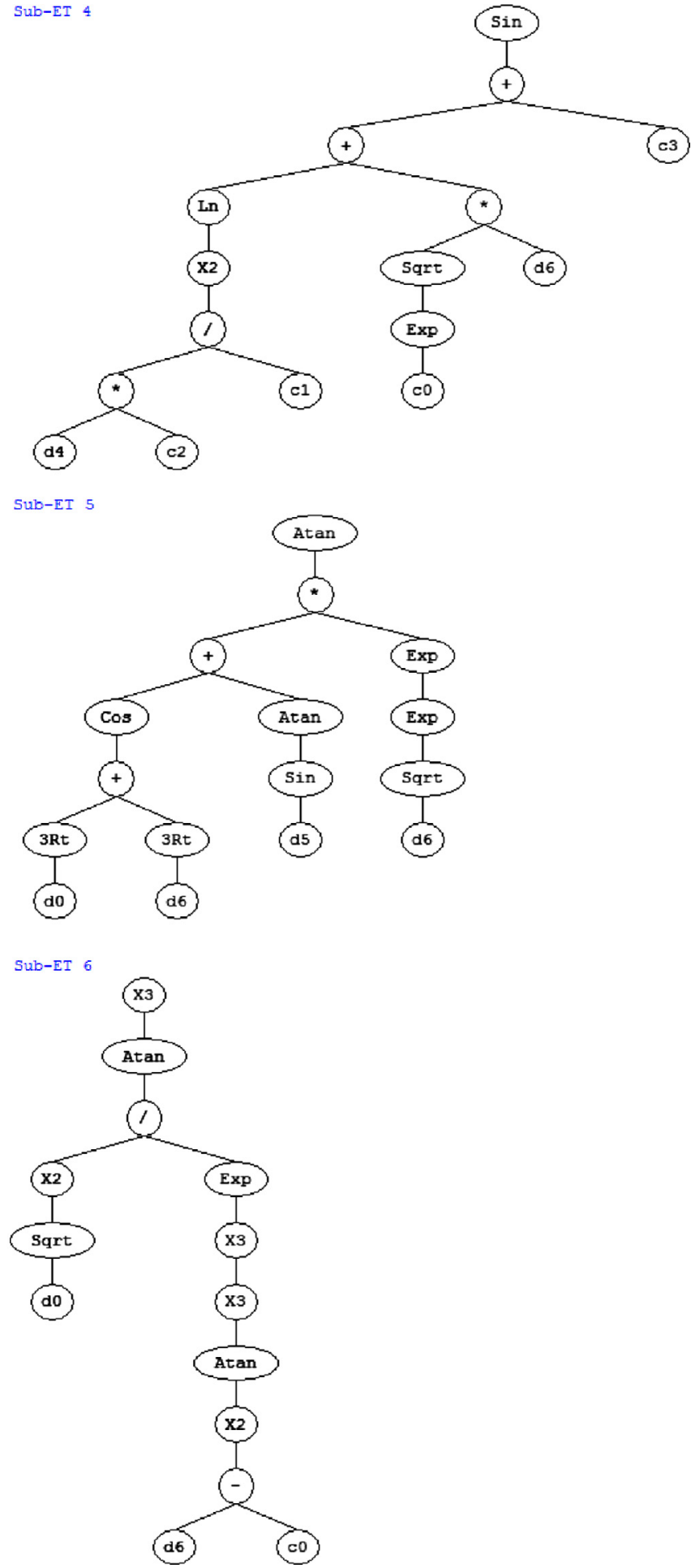

Fig. 3. Expression tree with 6 gens and addition as linking function for predicting compressive strength values of different geopolymers in GEP2 model.

the length of the head and the number of genes" (Sarıdemir, 2010). For all of GEP1-GEP6 approach models, initially a single gene and two lengths of heads were used, and the number of genes and heads were increased one after another during each run. The training and testing sets performance of each model were monitored. For GEP1-GEP3 approach models, the length of heads of 12 and for GEP4-GEP6 that of 14 was observed the best value. Parameters of the training of GEP1-GEP6 models are given in Table 2. For GEP1-GEP3 models, 30 and for GEP4-GEP6 models, 40 chromosomes were observed to be the best of generation individuals for predicting the compressive strength of different considered geopolymers. Explicit formulations based on the GEP1-GEP6 models for compressive strength were obtained by:

$i=f(T, C, S, N, M, A, H)$

\section{Results and discussion}

In this study, the error arose during the training, validating and testing. In GEP1-GEP6 models it can be expressed as absolute 

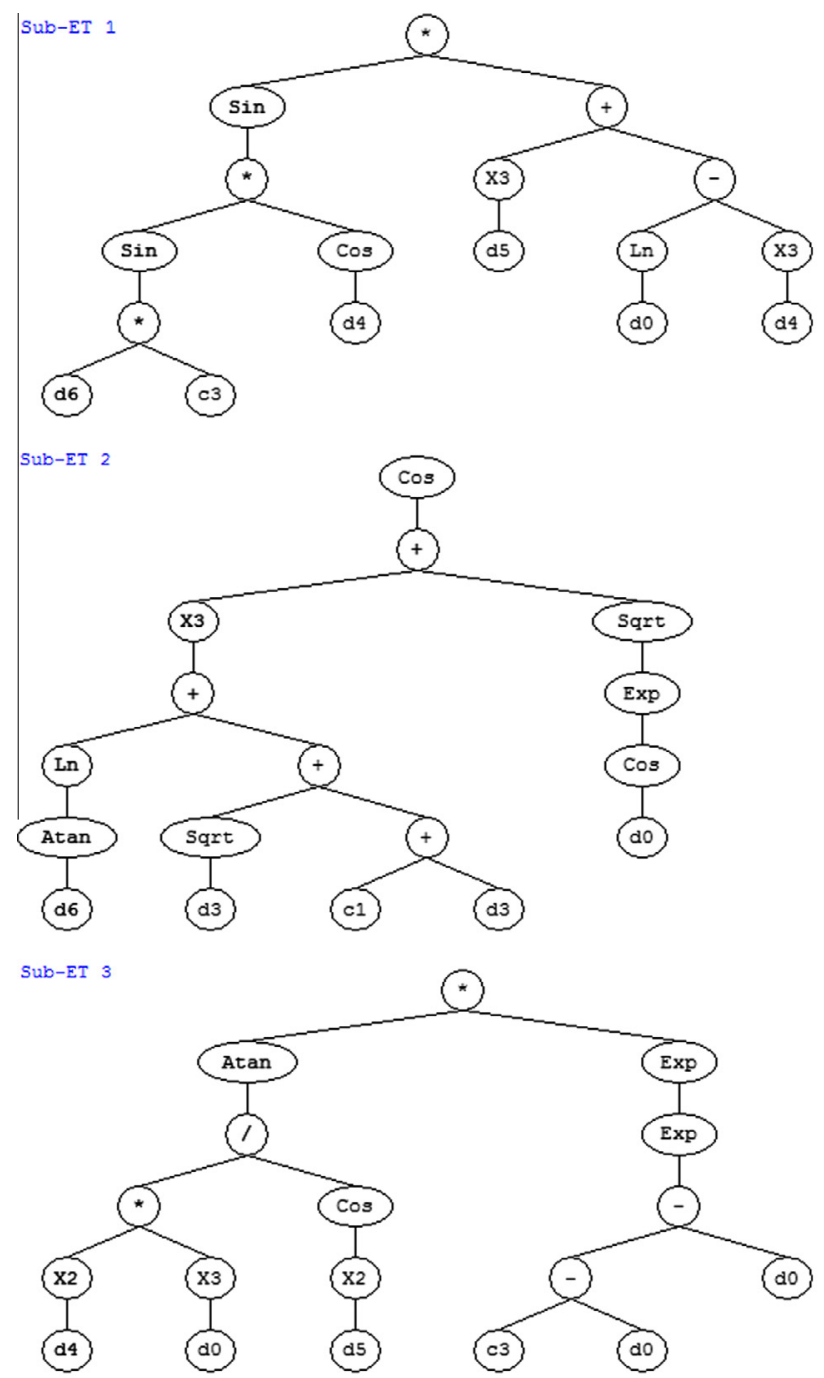

(d)
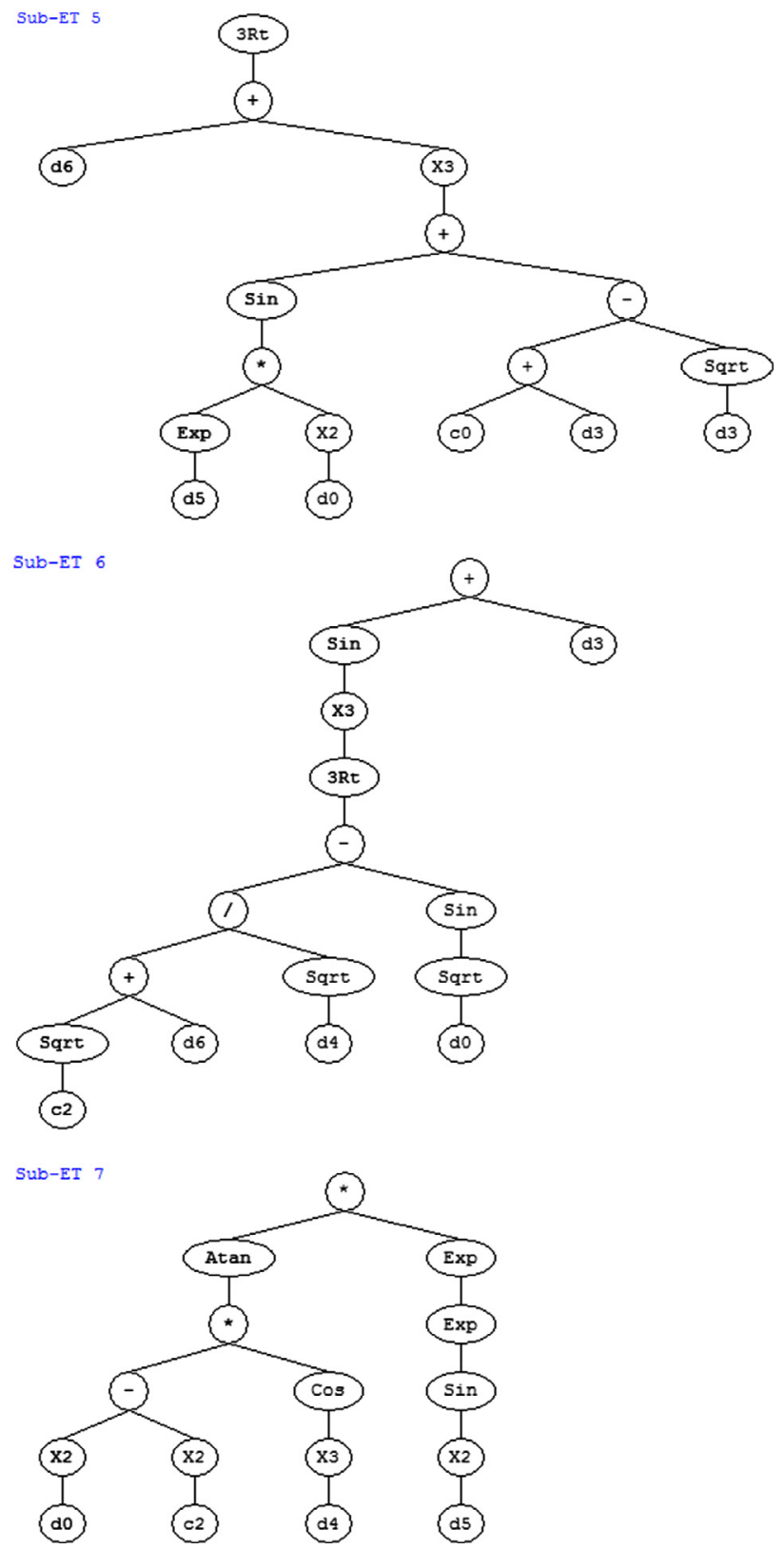

Fig. 4. Expression tree with 7 gens and addition as linking function for predicting compressive strength values of different geopolymers in GEP3 model.

fraction of variance $\left(R^{2}\right)$, the absolute percentage error (MAPE) and the root mean square error (RMSE) which are calculated by Eqs. (3)-(5), respectively Sarıdemir, 2010:

$R^{2}=1-\left(\frac{\sum_{i}\left(t_{i}-o_{i}\right)^{2}}{\sum_{i}\left(o_{i}\right)^{2}}\right)$

$\mathrm{MAPE}=\frac{1}{n} \sum_{i}\left|\frac{t_{i}-o_{i}}{t_{i}}\right| \times 100$

$\mathrm{RMSE}=\sqrt{\frac{1}{n} \sum_{i}\left(t_{i}-o_{i}\right)^{2}}$

where $t$ is the target value, $\mathrm{o}$ is the output value and $n$ is the number of data sets in each of the training and testing phases.

All of the results obtained from the experimental studies gathered from the literature and those predicted by using the training and testing results of GEP1-GEP6 models, are given in Figs. 8-13, respectively.

The equation of the constructed network obtained from Figs. 27, respectively for GEP1-GEP6 models can be stated as Eqs. (6)(11):

$$
\begin{aligned}
F_{S}(\mathrm{GEP} 1)= & N+(\sin (-2.64 H+1.67))^{3}-\cos (\sin (N)) \\
& +\cos \left((\ln (H))^{3}-\sin (M \cdot A)\right)+\left(\frac{4.89}{M}\right)^{2}-\sin \sqrt{T} \\
& +\ln (A)+\left(-1.03 A \cdot \cos ^{\frac{1}{3}}(\operatorname{Arctan}(T))\right)^{3} \\
& +\frac{\sin \left(\frac{N^{4}}{H-10.13}\right)}{\ln (\operatorname{Arctan}(\ln (H-1.79)))} \\
& +\cos \left(\frac{1}{3} \ln (2 A)+(60.5-H)^{2}+1.66 M+\operatorname{Arctan}(T)\right)
\end{aligned}
$$



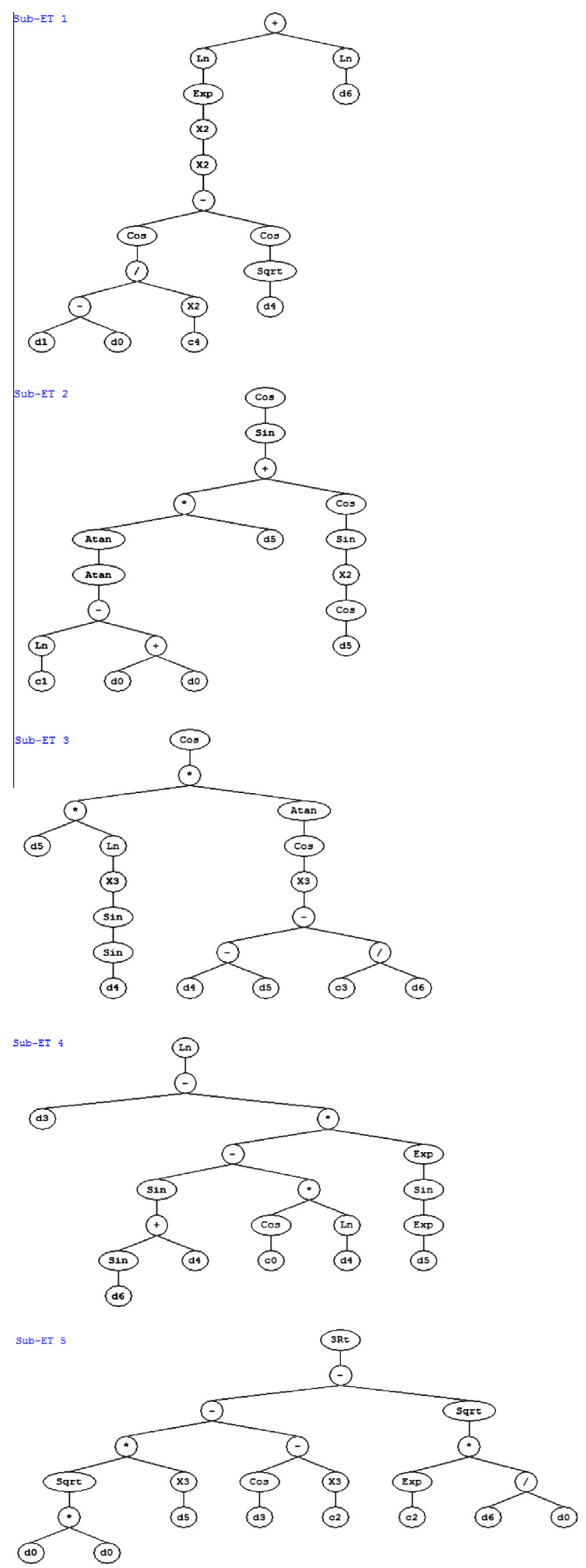

Fig. 5. Expression tree with 5 gens and multiplication as linking function for predicting compressive strength values of different geopolymers in GEP4 model.

$$
\begin{aligned}
& F_{S}(\mathrm{GEP} 2)=\frac{d 3 \cdot \operatorname{Arctan}\left(\frac{T}{A}\right)^{2}}{M^{4}+\operatorname{Arctan}(M) \cdot \ln (A)} \\
& +\operatorname{Exp}^{2}\left(\cos ^{3}(\cos (M+\sin (H)+2.19-\operatorname{Arctan}(\operatorname{Arctan}(M))))\right) \\
& +N+\sin (7.34+2 \ln (-0.56 M)+25.8 H) \\
& +\operatorname{Arctan}(\operatorname{Exp}(\operatorname{Exp} \sqrt{H}) \cdot(\operatorname{Arctan}(\sin (A))+\cos (\sqrt[3]{T}+\sqrt[3]{H}))) \\
& +\operatorname{Arctan}^{3}\left(\frac{T}{\operatorname{Exp}\left(\operatorname{Arctan}^{27}(H-9.67)^{2}\right)}\right) \\
& F_{s}(\mathrm{GEP} 3)=\sin (\sin (-2.81 d 6) \cdot \cos (d 4)) \cdot\left(d 5^{3}-d 4^{3}+\ln (d 0)\right) \\
& +\cos \left((\ln (\operatorname{Arctan}(d 6))+\sqrt{d 3}+d 3+0.17)^{3}+\sqrt{\operatorname{Exp}(\cos (d 0))}\right) \\
& +\operatorname{Arctan}\left(\frac{d 4^{2} \cdot d 0^{3}}{\cos \left(d 5^{2}\right)}\right) \cdot \operatorname{Exp}(\operatorname{Exp}(2.71-2 d 0))+\ln (d 0) \\
& +\sqrt[3]{d 6+\left(\sin \left(d 0^{2} \cdot \operatorname{Exp}(d 5)\right)-1.72+d 3-\sqrt{d 3}\right)^{3}}+d 3 \\
& +\sin \left(\frac{d 6+2.57}{\sqrt{d 4}}-\sin \sqrt{d 0}\right)+\operatorname{Arctan}\left(\left(d 0^{2}-10 \cdot 6\right) \cdot \cos \left(d 4^{3}\right)\right) \\
& F_{s}(\mathrm{GEP} 4)=\left(\ln \left(H+(\cos (0.02(C-T))-\cos \sqrt{M})^{4}\right)\right) \\
& \cos \left(\sin \left(\cos \left(\sin \left(\cos ^{2}(A)\right)\right)+A \cdot \operatorname{Arctan}(\operatorname{Arctan}(2.22-2 T))\right)\right) \\
& \cos \left(d 5 \cdot \ln \left(\sin ^{3}(\sin (M))\right) \cdot \ln \left(\operatorname{Arctan}\left(\cos \left(M-A-\frac{2.38}{H}\right)^{3}\right)\right)\right) \\
& \ln (N-(\sin (\sin (H)+M) \ln (M)) \cdot \operatorname{Exp}(\sin (\operatorname{Exp}(A)))) \\
& \cdot \sqrt[3]{T \cdot A^{3}-\cos (N)+973.2-141.9 \sqrt{\frac{H}{T}}}
\end{aligned}
$$$$
F_{S}(\mathrm{GEP} 5)=\ln (N) \cdot \operatorname{Arctan}\left(\sqrt[3]{H}-\sin ^{3}(-4.85 \sqrt{M} \cdot H \cdot \operatorname{Exp}(H))^{2}\right)^{4} .
$$$$
\sqrt{\operatorname{Arctan}\left(T \cdot((N+C-T-0.57 H) \cdot \cos (\operatorname{Exp}(A)))^{-\frac{2}{3}}\right)}
$$$$
\cdot \sqrt{9.56+\sin (\sqrt{H} \cdot(N-1.19)+\sqrt[3]{2 M}+1.95)}
$$$$
\sqrt{9.99 \operatorname{Arctan}\left(N-\left(\ln \left(N \cdot M-\cos (H)+\ln \left(\frac{2.71}{N}\right)\right)\right)^{2}\right)}
$$$$
\frac{\operatorname{Arctan}(\sin \sqrt[8]{\sqrt{3.31 A}-d 0+\sin (H)})}{M}
$$$$
F_{S}(\mathrm{GEP} 6)=\operatorname{Arctan}\left(T+\sin ^{4}(\operatorname{Exp}(\sin (\cos (N . H)-0.0005 N)))\right)
$$$$
\operatorname{Arctan}((M+N-\operatorname{Exp}(\operatorname{Arctan}(M \cdot H))) \cdot \operatorname{Exp}(\cos (N+H-M-7.39)))
$$$$
\operatorname{Arctan}\left(-9.54+\sqrt{0.0001 \operatorname{Exp}(S-C) \cdot \operatorname{Exp}(M-8.31)^{2}}\right) \cdot(2 \ln (H))^{\frac{1}{3}} \text {. }
$$$$
\sqrt{N-\cos \left(\operatorname{Exp}\left(\sin \left(d 5^{3} \cdot(H+T+\operatorname{Arctan}(H))\right)\right)\right)} .
$$$$
\sqrt[3]{\left(\operatorname{Exp}\left(\operatorname{Arctan}\left((A-H-S+8.29) \cdot A^{3}\right)\right)+(\operatorname{Arctan}(N)+2.32)^{1.5}\right)}
$$$$
\frac{\operatorname{Arctan} \sqrt[3]{(M-138)^{3}-143-\sin \left(H^{3}\right)-\frac{7.71}{A}}}{M}
$$

$R^{2}$, MAPE and RMSE values of GEP1-GEP6 models are shown in Table 3 for the training and testing data.

The interesting point is that utilizing addition as linking function between Sub-ETs does not result in a high performance model 


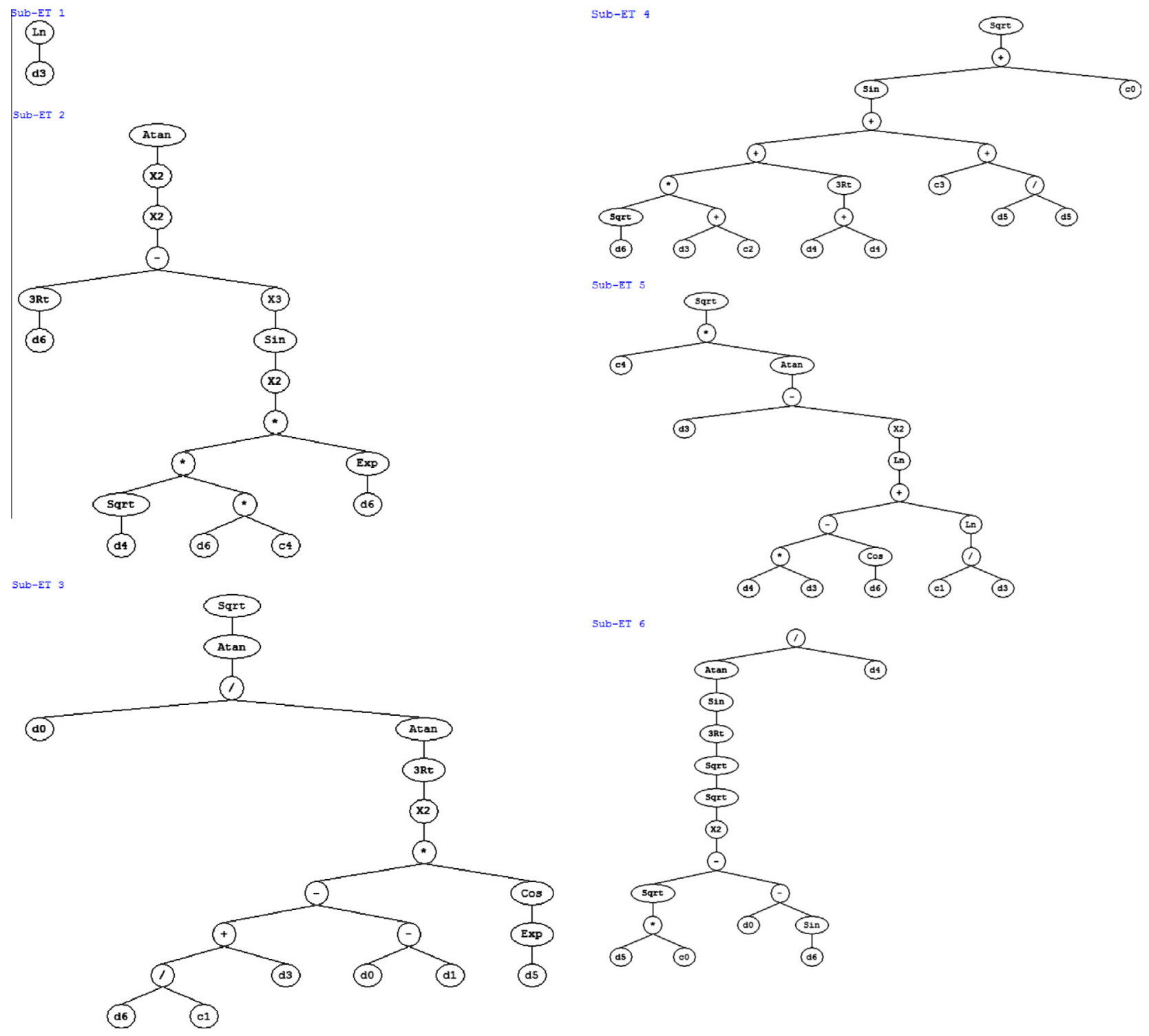

Fig. 6. Expression tree with 6 gens and multiplication as linking function for predicting compressive strength values of different geopolymers in GEP5 model.

(in comparison to all of the models with multiplication as linking function). Although all of the obtained results using selecting addition as linking function are good enough to be used, one may employ multiplication as linking function, with smaller number of Sub-ETs, and with higher performance.

This is visible in Figs. 8-13 where the values obtained from the training and testing in GEP1-GEP6 models are very close to those of the experimental results.

The highest performance model between GEP1 and GEP3 models with addition as linking function, is related to GEP3 model with $R^{2}$, MAPE and RMSE values of 0.9556, 2.4601 and 3.4716 for training phase, respectively and $0.9483,2.8456$ and 3.7959 for testing phase, respectively.

Our attempts to construct a model with higher number of genes resulted in lower performance models. Therefore, one may suggest that by utilizing addition as linking function, employing 7 Sub-ETs could result in the best performance network. On the other hand, between GEP4 and GEP6 models, with multiplication as linking function, the best performance model is GEP5 model with $R^{2}$,
MAPE and RMSE values of $0.9547,2.5665$ and 3.4360 for training phase, respectively and $0.9466,2.8020$ and 3.8047 for testing phase, respectively. After that, the performance of the models decreases. In conclusion, one may suggest that by employing multiplication as linking function, 6 Sub-ETs use could result in the highest performance approach model.

As shown in Figs. 8-13, the predicted results from the models are compared to the experimental results for training and testing sets, respectively. The training set results proved that the proposed models have (impressively well) learned the non-linear relationship between the input and the output variables, with high correlation and comparatively low error values. Comparing the GEP1-GEP6 approach models predictions with the experimental results for the testing and training stages demonstrates a high generalization capacity of the proposed models and comparatively low error values. All of these findings exhibit a successful performance of the models for predicting compressive strength values of the considered geopolymers in training and testing stages. 


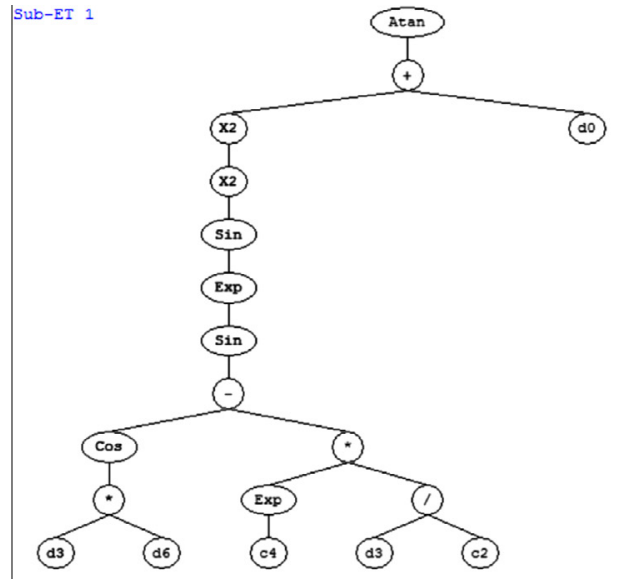

Sub-ET 2
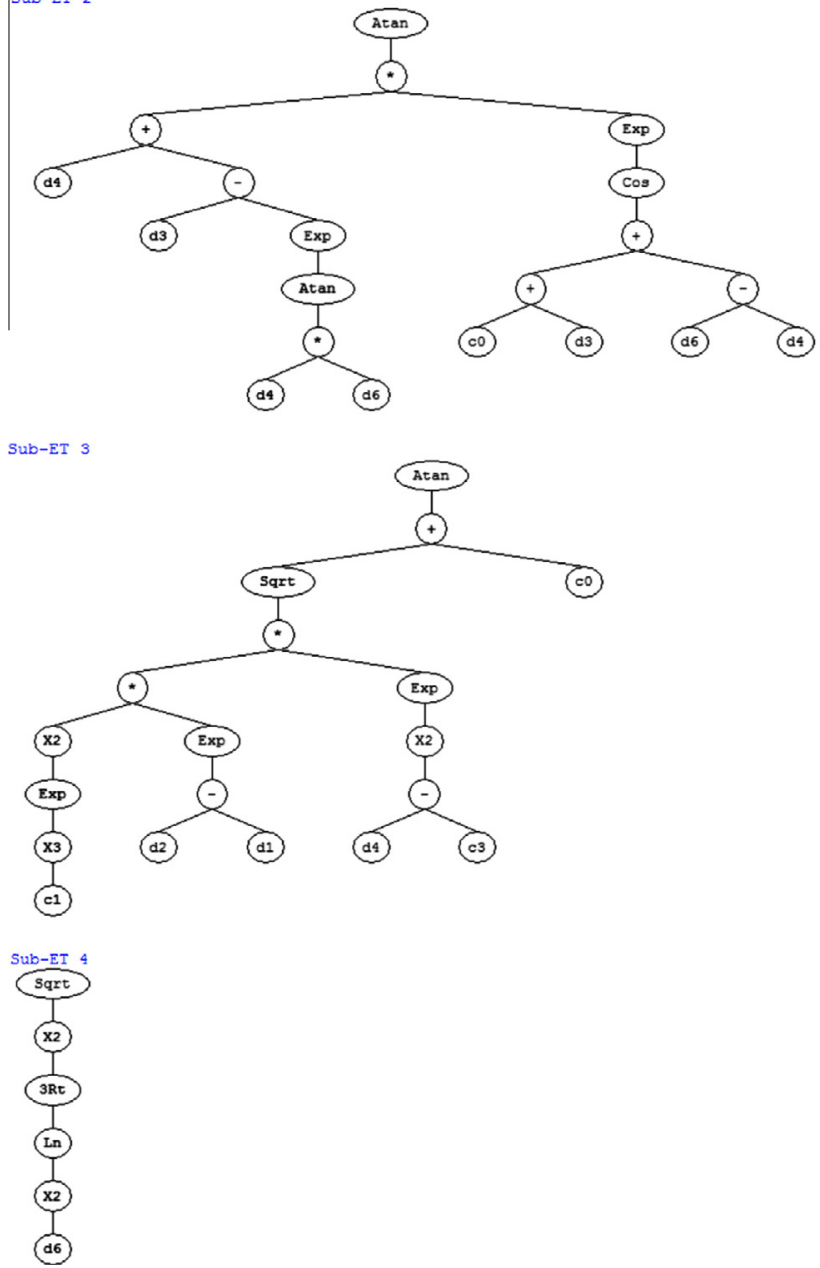

Fig. 7. Expression tree with 7 gens and multiplication as linking function for predicting compressive strength values of different geopolymers in GEP6 model.

The result of the testing phase in Figs. 8-13 shows that GEP1GEP6 models are capable of generalizing between input and output variables with reasonably good predictions. The performance of the GEP1-GEP6 models is shown in Table 3.

The best value of $R^{2}$, and the minimum value of MAPE and RMSE are $0.9556,2.4601$ and 3.4360, respectively all in training phase of GEP5, GEP5 and GEP3 models, in that order. The minimum value of $R^{2}$ and the maximum value of MAPE and RMSE are 0.8792, 3.6597 and 5.6945, respectively, all for testing set in GEP2 model. All of $R^{2}$, MAPE and RMSE values show that the proposed GEP1-GEP6 models are suitable and can predict compressive strength values of geopolymers close to the experimental ones.
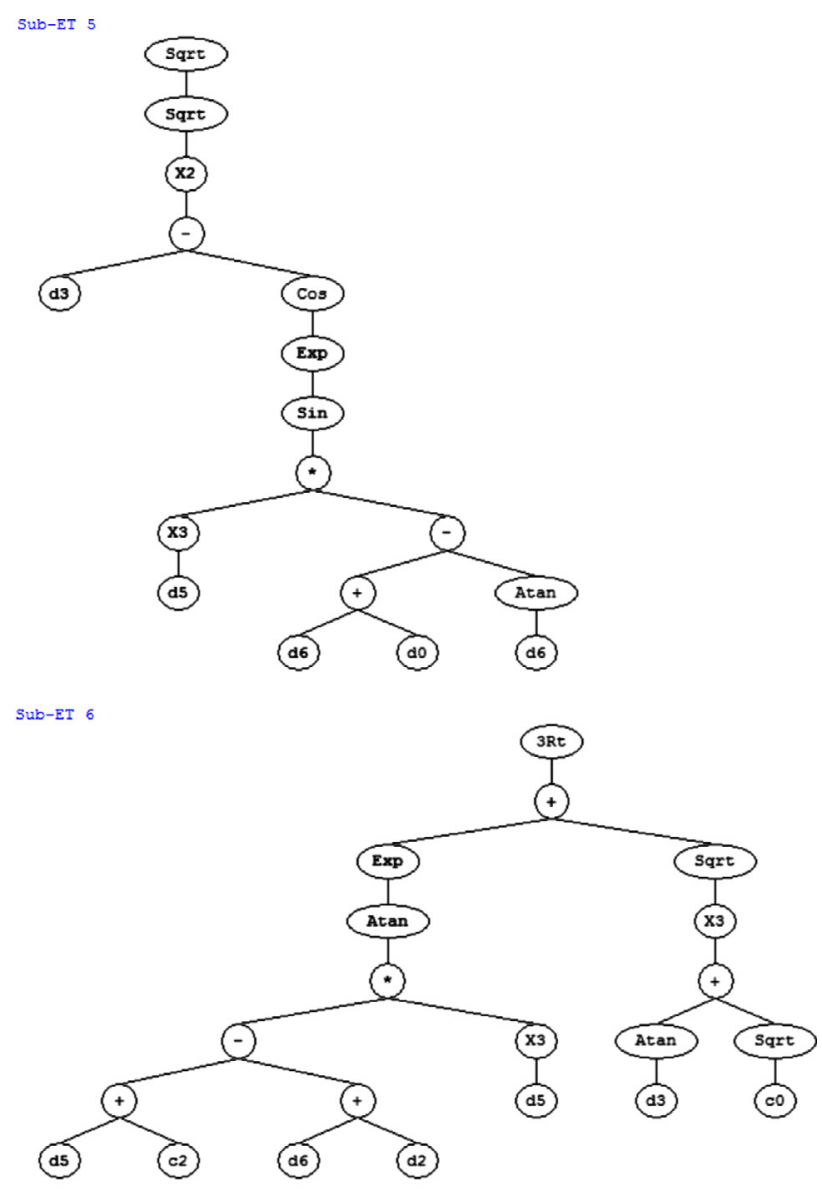

Sub-ET

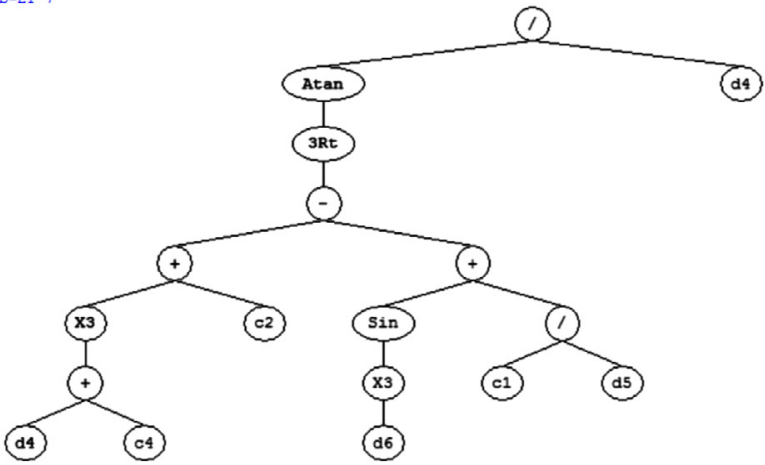

Finally, Fig. 14 shows fitness factor vs. generation iteration for GEP1-GEP6 models, respectively. This figure shows that GEP1GEP6 models are suitably trained and the final results in the studied range are of such reliability that one may consider these models for predicting compressive strength of the considered geopolymers.

\section{Conclusions}

This study investigates the compressive strength of different geopolymers by GEP models. Six different models named 
Table 1

The range of input and output variables considered for GEP1 to GEP6 models.

\begin{tabular}{ll}
\hline Variable & Range \\
\hline Curing time (days) & $1-90$ \\
$\mathrm{Ca}(\mathrm{OH})_{2}$ content $(\mathrm{Wt} \%)$ & $0-22.5$ \\
The amount of superplasticizer (Wt\%) & $0-3$ \\
$\mathrm{NaOH}$ concentration (M) & $6-24$ \\
Mold type & $1-2$ \\
Aluminosilicate source & $1-3$ \\
$\mathrm{H}_{2} \mathrm{O} / \mathrm{Na}_{2} \mathrm{O}$ molar ratio & $8.9-19.1$ \\
$\mathrm{Compressive} \mathrm{strength} \mathrm{(MPa)}$ & $1.5-75.2$ \\
\hline
\end{tabular}

Table 2

Parameters of GEP approach models.

\begin{tabular}{llll}
\hline Parameter definition & GEP-I & GEP-II \\
\hline P1 & Chromosomes & 30 & 40 \\
P2 & Head size & 12 & 14 \\
P3 & Linking function & Addition & Multiplication \\
P4 & Mutation rate & 0.044 & 0.044 \\
P5 & Inversion rate & 0.1 & 0.1 \\
P6 & One-point recombination rate & 0.3 & 0.3 \\
P7 & Two-point recombination rate & 0.3 & 0.3 \\
P8 & Gene recombination rate & 0.1 & 0.1 \\
P9 & Gene transposition rate & 0.1 & 0.1 \\
P10 & Constants per gene & 5 & 5 \\
P11 & Weight of functions & 7 & 7 \\
P12 & Upper bound & 10 & 10 \\
P13 & Lower bound & -10 & -10 \\
\hline
\end{tabular}
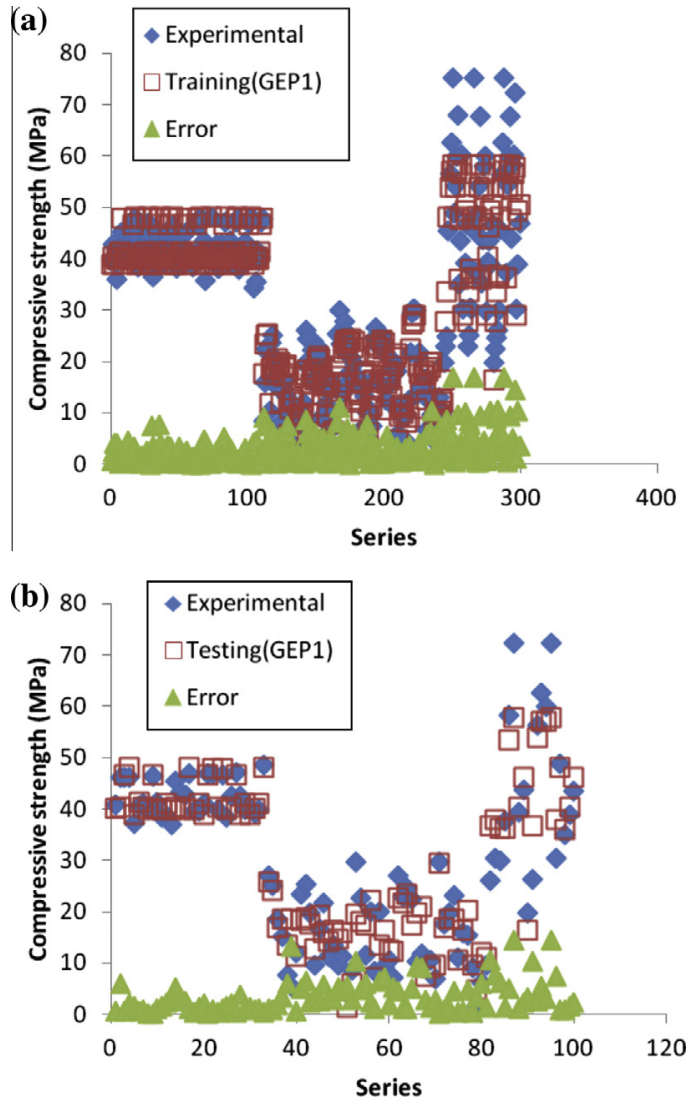

Fig. 8. The correlation of the measured and predicted compressive strength values in (a) training and (b) testing phase for GEP1 model.
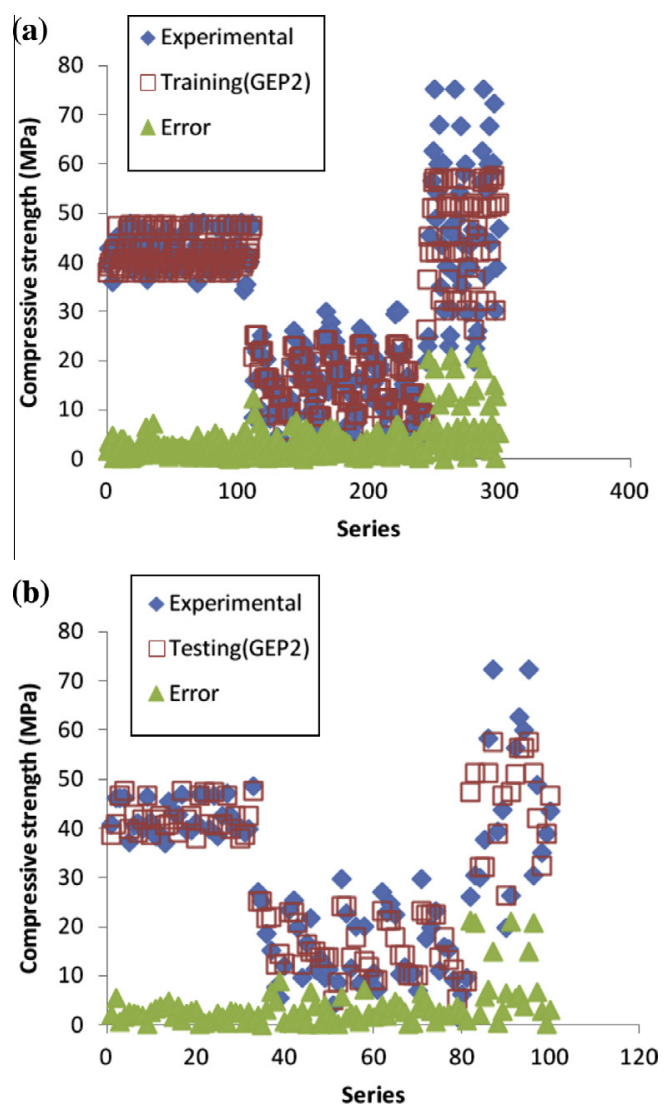

Fig. 9. The correlation of the measured and predicted compressive strength values in (a) training and (b) testing phase for GEP2 model.
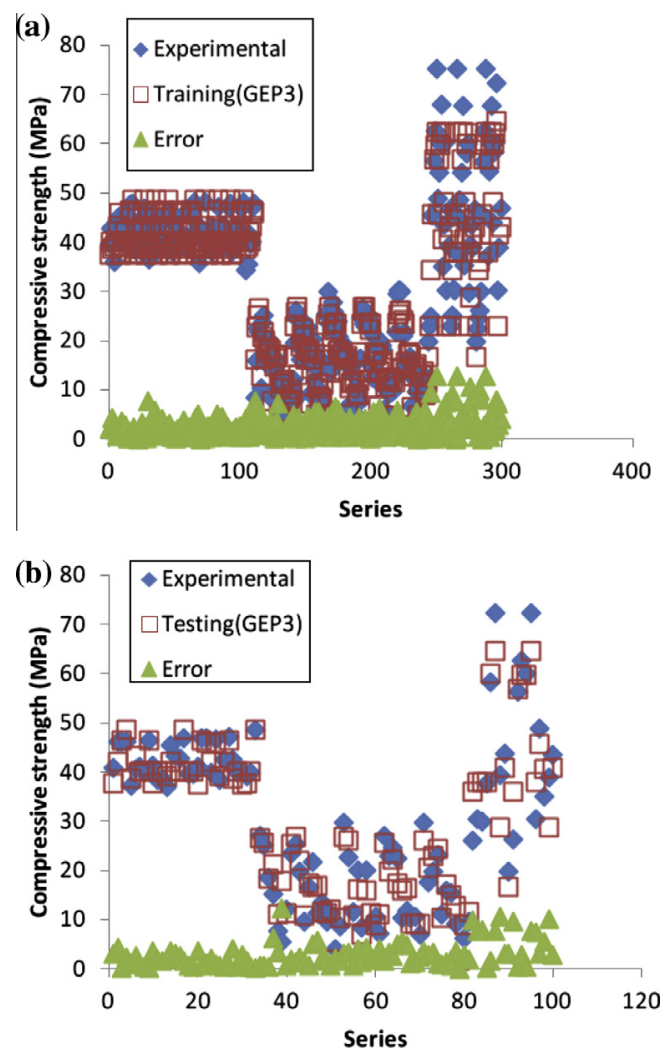

Fig. 10. The correlation of the measured and predicted compressive strength values in (a) training and (b) testing phase for GEP3 model. 

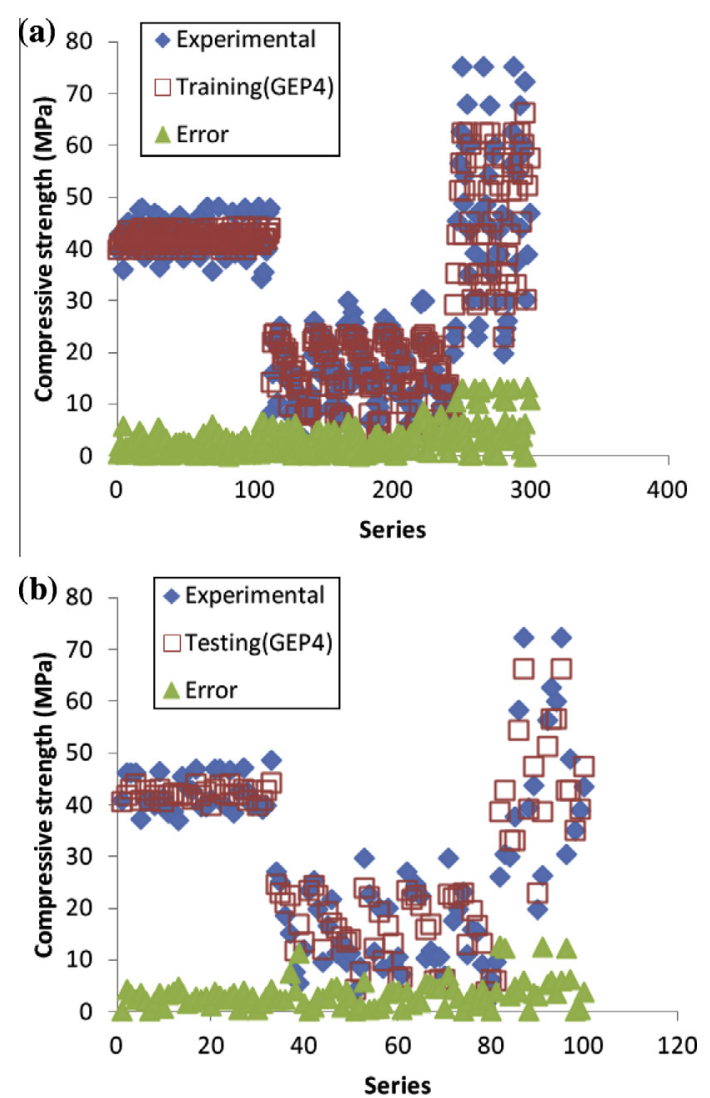

Fig. 11. The correlation of the measured and predicted compressive strength values in (a) training and (b) testing phase for GEP4 model.
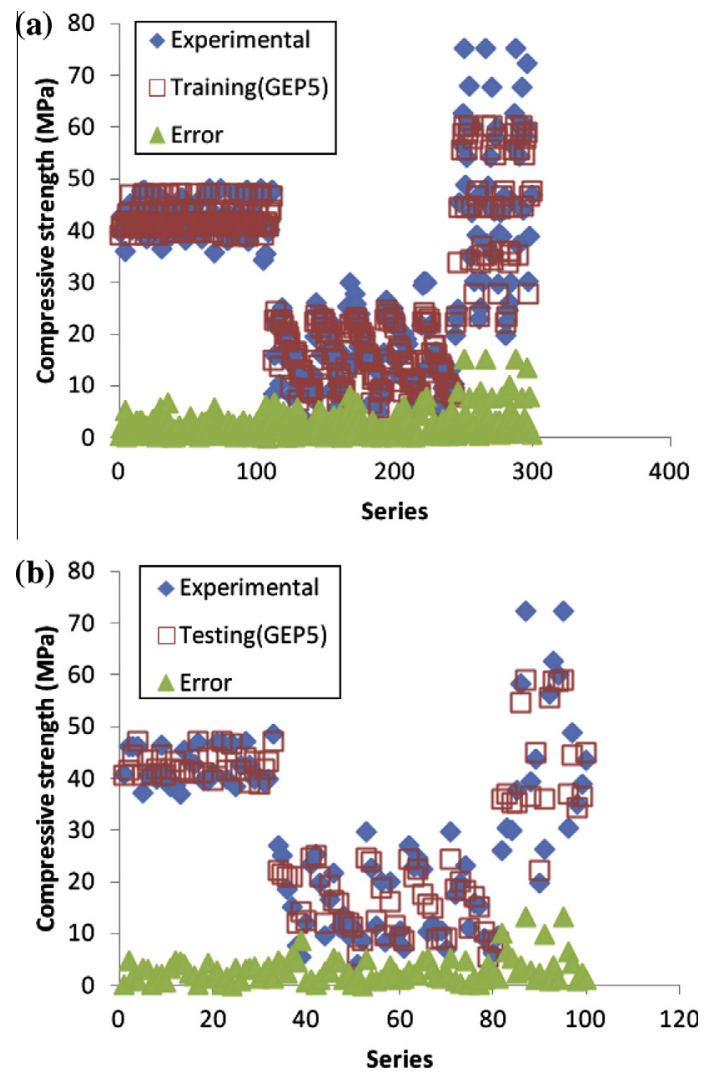

Fig. 12. The correlation of the measured and predicted compressive strength values in (a) training and (b) testing phase for GEP5 model.
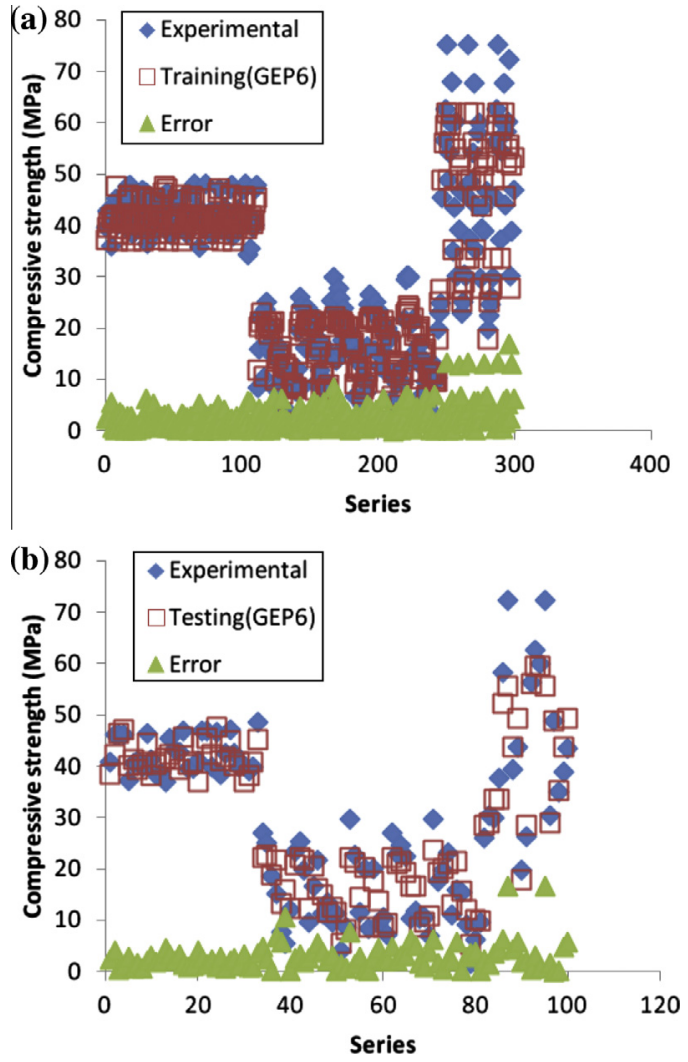

Fig. 13. The correlation of the measured and predicted compressive strength values in (a) training and (b) testing phase for GEP6 model.

Table 3

Statistical calculations from GEP1 to GEP6 training and testing phases.

\begin{tabular}{|c|c|c|c|c|c|c|}
\hline \multirow[t]{2}{*}{ Models } & \multicolumn{2}{|l|}{$R^{2}$} & \multicolumn{2}{|l|}{ MAPE } & \multicolumn{2}{|l|}{ RMSE } \\
\hline & Training & Testing & Training & Testing & Training & Testing \\
\hline GEP1 & 0.9375 & 0.9230 & 2.8479 & 3.3501 & 4.0446 & 4.5867 \\
\hline GEP2 & 0.9018 & 0.8792 & 3.3623 & 3.6597 & 5.0521 & 5.6945 \\
\hline GEP3 & 0.9547 & 0.9466 & 2.5665 & 2.8020 & 3.4360 & 3.8047 \\
\hline GEP4 & 0.9395 & 0.9345 & 2.9338 & 3.2796 & 3.9942 & 4.2276 \\
\hline GEP5 & 0.9556 & 0.9483 & 2.4601 & 2.8456 & 3.4716 & 3.7959 \\
\hline GEP6 & 0.9509 & 0.9441 & 2.6387 & 2.9270 & 3.6027 & 4.0093 \\
\hline
\end{tabular}

GEP1-GEP6 were proposed, where the number of Sub-ETs and linking functions are changed from 5 to 7 and from addition to multiplication, respectively. In addition, the number of chromosomes and head sizes were different. The proposed models are empirical and based on experimental results collected from the previous works. All of the results obtained from the models show suitable agreement with experimental results. The statistical values of $R^{2}$, MAPE and RMSE have revealed this situation. However, the best performance network was obtained by utilizing 6 SubETs and multiplication as linking function where $R^{2}$, MAPE and RMSE values of $0.9547,2.5665$ and 3.4360 for training phase, respectively and $0.9466,2.8020$ and 3.8047 for testing phase, respectively were acquired. It was found that GEP can be an alternative approach for the evaluation of the compressive strength of the considered geopolymers. Comparison between GEP in terms of $R^{2}$, MAPE and RMSE showed that GEP models are capable to predict suitable results for the compressive strength values as they are very close to the experimental ones. 

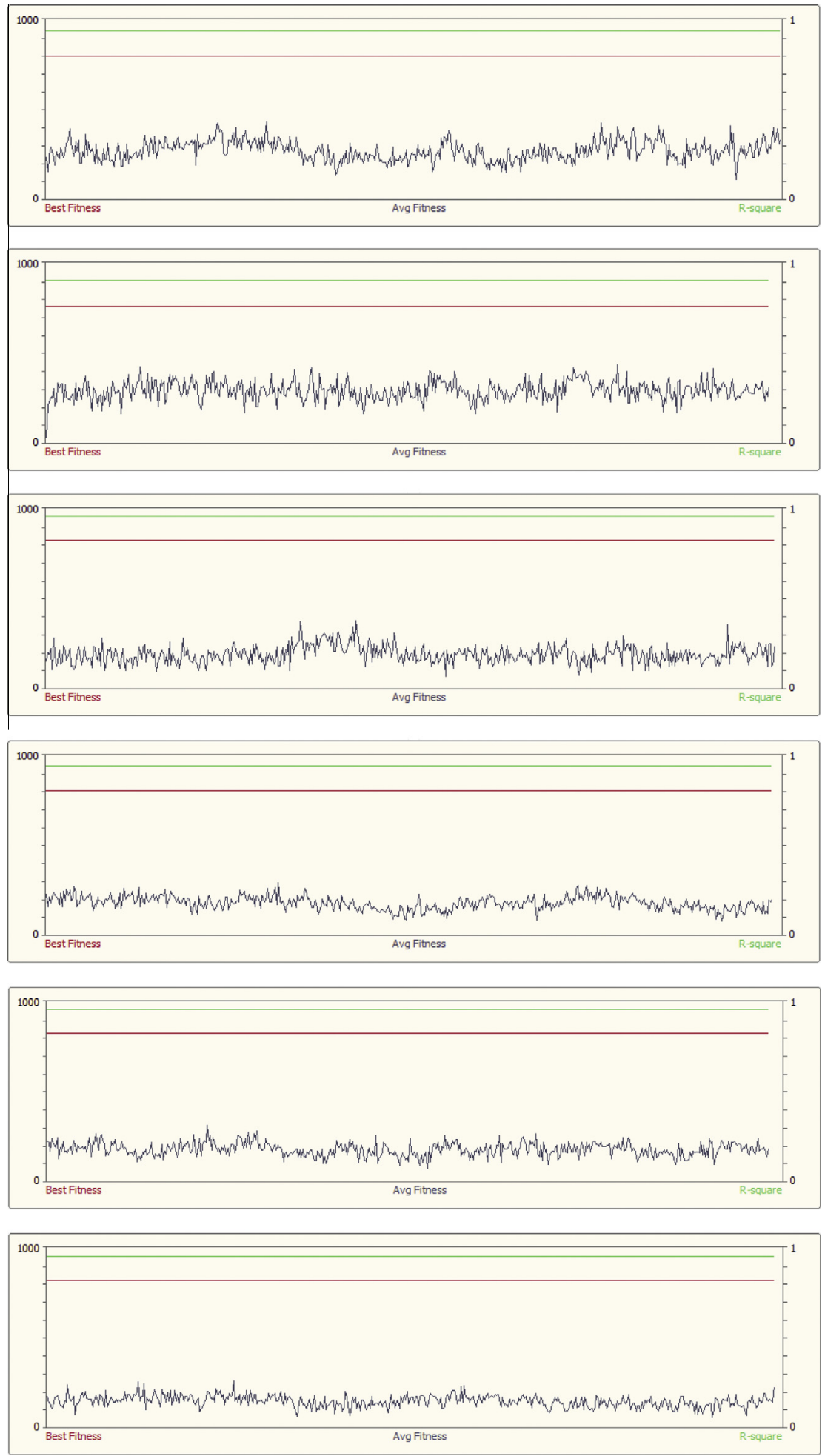

Fig. 14. Fitness factor vs. generation iteration for (a) GEP1, (b) GEP2, (c) GEP3, (d) GEP4, (e) GEP5 and (f) GEP6 models.

\section{References}

Bernal, S., Gutierrez, R. D., Delvasto, S., \& Rodriguez, E. (2010). Performance of an alkali-activated slag concrete reinforced with steel fibers. Construction and Building Materials, 24, 208-214.

Cevik, A., \& Sonebi, M. (2009). Genetic programming based formulation for fresh and hardened properties of self-compacting concrete containing pulverised fuel ash. Construction and Building Materials, 23(7), 2614-2622.

Chindaprasirt, P., Chareerat, T., \& Sirivivatnanon, V. (2007). Workability and strength of coarse high calcium fly ash geopolymer. Cement $\mathcal{E}$ Concrete Composites, 29, 224-229.
Duxson, P., Provis, J., Van Lukey, G., \& Deventer, J. (2007). The role of inorganic polymer technology in the development of green concrete. Cement and Concrete Research, 37, 1590-1597.

He, J., Zhang, J., Yu, Y., \& Zhang, G. (2012). The strength and microstructure of two geopolymers derived from metakaolin and red mud-fly ash admixture: A comparative study. Construction and Building Materials, 30, 80-91.

Koza, J. R. (1992). Genetic programming: on the programming of computers by means of natural selection. Cambridge (MA, USA): MIT Press.

Lemougna, P. N., MacKenzie, K. J. D., \& Melo, U. F. C. (2011). Synthesis and thermal properties of inorganic polymers (geopolymers) for structural and refractory applications from volcanic ash. Ceramics International, 37, 3011-3018. 
Muñiz-Villarreal, M. S., Manzano-Ramírez, A., Sampieri-Bulbarela, S., Ramón GascaTirado, J., Reyes-Araiza, J. L., Rubio-Ávalos, J. C., et al. (2011). The effect of temperature on the geopolymerization process of a metakaolin-based geopolymer. Materials Letters, 65, 995-998.

Nazari, A. (2012a). Compressive strength of geopolymers produced by ordinary Portland cement: Application of genetic programming for design. Materials and Design. http://dx.doi.org/10.1016/j.matdes.2012.07.012.

Nazari, A. (2012b). Experimental study and computer-aided prediction of percentage of water absorption of geopolymers produced by waste fly ash and rice husk bark ash. International Journal of Mineral Processing, 110-111, 74-81.

Nazari, A., Bagheri, A., \& Riahi, S. (2011). Properties of geopolymer with seeded fly ash and rice husk bark ash. Materials Science and Engineering A, 528, 7395-7401.

Nazari, A., Riahi, S., Khalaj, G., Bohlooli, H., \& Kaykha, M. M. (2011). Prediction of compressive strength of geopolymers with seeded fly ash and rice husk-bark ash by gene expression programming. International Journal of Damage Mechanics. http://dx.doi.org/10.1177/1056789511431991.

Onisei, S., Pontikes, Y., van Gerven, T., Angelopoulos, G. N., Velea, T., Predica, V., et al. (2012). Synthesis of inorganic polymers using fly ash and primary lead slag. Journal of Hazardous Materials, 205-206, 101-110.

Pacheco Torgal, F., Gomes, J. P., \& Jalali, S. (2008). Alkali - Activated binders: A review Part 2 About materials and binders manufacture. Construction and Building Materials, 22, 1315-1322.

Pacheco-Torgal, F., Castro-Gomes, J., \& Jalali, S. (2007). Investigations about the effect of aggregates on strength and microstructure of geopolymeric mine waste mud binders. Cement and Concrete Research, 37, 933-941.

Pacheco-Torgal, F., Castro-Gomes, J. P., \& Jalali, S. (2008a). Alkali - Activated binders: A review Part 1 Historical background, terminology, reaction mechanisms and hydration products. Construction and Building Materials, 22, 1305-1314.

Pacheco-Torgal, F., Castro-Gomes, J. P., \& Jalali, S. (2008b). Investigations on mix design of tungsten mine waste geopolymeric binder. Construction and Building Materials, 22, 1939-1949.

Pacheco-Torgal, F., Moura, D., Yining Ding \& Jalali, S. (2011). Composition, strength and workability of alkali-activated metakaolin based mortars. Construction and Building Materials, 25, 3732-3745.

Sarıdemir, M. (2010). Genetic programming approach for prediction of compressive strength of concretes containing rice husk ash. Construction and Building Materials, 24, 1911-1919.

Tailby, J., \& MacKenzie, K. J. D. (2010). Structure and mechanical properties of aluminosilicate geopolymer composites with Portland cement and its constituent minerals. Cement and Concrete Research, 40, 787-794.

Tanyildizi, H., \& Cevik, A. (2010). Modeling mechanical performance of lightweigh concrete containing silica fume exposed to high temperature using genetic programming. Construction and Building Materials, 24, 2612-2618.

Temuujin, J., Minjigmaa, A., Lee, M., Chen-Tan, N., \& van Riessen, A. (2011) Characterisation of class $\mathrm{F}$ fly ash geopolymer pastes immersed in acid and alkaline solutions. Cement E' Concrete Composites, 33, 1086-1091.

Tsai, H. C. (2011). Weighted operation structures to program strengths of concretetyped specimens using genetic algorithm. Expert Systems with Applications, 38(1), 161-168.

Wang, M. R., Jia, D. C., He, P. G., \& Zhou, Y. (2011). Microstructural and mechanica characterization of fly ash cenosphere/metakaolin-based geopolymeric composites. Ceramics International, 37, 1661-1666. 